\title{
Relationship of body perception and stress with obesity, food consumption and eating disorders among working women
}

\begin{abstract}
Aatma Singh*
Department of Home Science, Khalsa College for Women, Jalandhar (Punjab), India Kiran Bains

Department of Food and Nutrition, Punjab Agricultural University, Ludhiana (Punjab), India

*Corresponding author. E-mail: aa_singh8@yahoo.com

Abstract

The influence of body perception and stress on the rising trend of obesity among working women was studied. Body perception, food frequency, stress and anthropometric parameters and body fat were assessed in female teachers aged 30-59 years from five colleges of Jalandhar, Punjab. Body satisfaction perceived as lesser concern with body shape was positively and significantly ( $\mathrm{s} \leq 0.01)$ correlated with $\mathrm{BMI}$, body weight, waist circumference and body fat. Body dissatisfaction in terms of higher concern with body shape was significantly correlated with lesser consumption frequency of traditional sweets $(p \leq 0.05)$. Body satisfaction was found to be significantly $(p \leq 0.01)$ correlated with uncontrolled eating and emotional eating. Stress level showed a positive and significant $(p \leq 0.01)$ correlation with the consumption of traditional savoury snacks, western fast food and higher frequency of eating out. The stress level was also significantly $(p \leq 0.05)$ correlated with emotional eating. The study concluded that adiposity, eating behaviours and food choices were influenced by stress and a lesser concern about body shape among working women.
\end{abstract}

Keywords: Body perception, Body fat, Eating Behaviour, Physical activity, Stress

\section{INTRODUCTION}

Obesity and overweight occur due to abnormal or excessive fat accumulation that may impair health. Asian Indians have a greater predisposition to abdominal obesity and accumulation of visceral fat and this has been termed as "Asian Indian phenotype or paradox" (Joshi, 2003). Many Indians fit into the category of metabolically obese, normal weight individuals (Unnikrishnan and Kalra, 2012). Obesity is clearly more prevalent in women worldwide. Women are naturally fatter, with less lean tissue than men and have to gain far more weight to accrue the additional lean tissue needed to provide the adaptive gain in basal metabolism to match any excessive intake (James, 2001).National Family Health Survey (NFHS-3) in 2005-2006 reported that prevalence of obesity among Indian women has elevated by $24.52 \%$ in the last decade. The prevalence is more profound in the women of aged between 4049 years $(23.7 \%)$, residing in cities $(23.5 \%)$, having high qualification (23.8\%) and households in the highest wealth quintile $(30.5 \%)$. In India, the highest percentage $(29.9 \%)$ of obese women was found in Punjab (Garg et al.,2009).

A women's body changes throughout the lifespan in terms of its shape as well as size (Sheehanet al.,2003). Body satisfaction is the extent to which

\section{Article Info}

DOI:10.31018/jans.v10i3.1844

Received: July 29, 2018

Revised: August 24, 2018

Accepted: August 30, 2018

\section{How to Cite}

Bains, K. and Singh, A. (2018). Relationship of body perception and stress with obesity, food consumption and eating disorders among working women. Journal of Applied and Natural Science, 10(3): 1066-1072 an individual is content and comfortable with one's appearance (Martin,2010). Negative implications of body dissatisfaction arise regardless of age (Peat et al., 2008). Through middle age, the increase in body mass index (BMI) and body size is observed to a greater extent which increases the susceptibility of body dissatisfaction with advancing age (Tiggemann and Lynch, 2001). Researchers have confirmed that negative perceptions of body image consequently lead to a higher risk of developing eating disorders (Keel et al.,2007) and depression (Benas et al., 2010) as well as reduced quality of life (Haraldstad et al.,2011).

Researchers have reported that psychological and physical factors contributing to stress stimulates the secretion of glucocorticoids and insulin which in turn increase the consumption of high-fat and high-sugar foods and a greater accumulation of visceral fat leading to a dampened hypothalamicpituitary-adrenal axis. Preliminary evidence from human studies indicated that chronic stress exposure is associated with increased consumption of palatable food, greater abdominal fat and dampened cortisol response to acute stress (Finch and Tomiyama, 2014). The present study was carried out with an objective to gain an insight about the influence of body perception and stress on overweight/obesity, food consumption and eating disorders among women. 


\section{MATERIALS AND METHODS}

Selection of subjects: One hundred volunteer female faculty members involved in similar kind of profession i.e. teaching job for 6-8 hours per day in the age group 30-59 years from five colleges of Jalandhar city of Punjab were enrolled for the study. The selected subjects were divided into three groups as Group I (30-39 years), Group II (40-49 years) and Group III (50-59 years) comprising 53, 26 and 21 subjects, respectively. A written consent of the subjects to participate in the study was obtained.

Data collection: The body shape questionnaire (BSQ-16) developed by Evans and Dolan (1993) was used. The questionnaire assesses the respondent's feelings about their appearance over the past four weeks. Each item is scored 1 to 6 with "1" assigned to "never" and "6" representing "always". The Perceived Stress Scale (PSS 10) was used which was developed by Cohen et al. (1983). The scale collects information about the feelings and thoughts of the subjects based on the past four weeks. Perceived Stress Scale scoring each item is rated on a 5-point scale ranging from never (0) to almost always (4). There are 10 items in total where items 4, 5, 7 and 8 are the positively stated items. The positively stated items are reverse scored, and the ratings are summed, with higher scores indicating more perceived stress. The Food Frequency Questionnaire designed by the Harvard School of Public Health for the health professionals' follow-up study was utilized after modification as per food pattern of Indians containing 147 items for maximal discrimination of the type of foods consumed. For the interpretation, code " 0 " was assigned to the response "never" up to the response code " 9 " which represents " $6+$ per day" (Harvard School of Public Nutrition, 2014). The three-factor eating questionnaire developed by Cappelleri et al.,(2009) was used. The TFEQR21 asks participants to respond to 21 questions on a four-point Likert scale for items 1-20 and on an eight-point numerical rating scale for item 21 . Responses to each of the items are given a score between 1 and 4 . Domain scores were then calculated as a mean of all items within each domain i.e. cognitive restraint (six items), uncontrolled eating (nine items) and emotional eating (six items) with higher scores being indicative of greater cognitive restraint, uncontrolled eating and emotional eating.

Anthropometric parameters and body fat measurement: The anthropometric measurements i.e. height $(\mathrm{cm})$, weight $(\mathrm{kg})$, waist and hip circumferences $(\mathrm{cm})$ were assessed using standard procedures. Body mass index and waist to hip ratio were derived. Reference cut off values of $>25 \mathrm{kgm}^{2}$ for BMI (Garrow, 1981) and >0.8 for waist and hip ratio value (Ghafoorunissa and Krishnaswamy, 1994) were used for the assessment of obesity. Body fat percentage was estimated through bioelectrical impedance analyzer (Tanita body composition monitor BC541) which allows a low level, imperceptible electric current to travel through the body and as BIA determines the resistance to the flow of current it provides estimates of the water from which fat is calculated using selected equations. Body fat percentage is the amount of body fat proportional to the body weight (Fat Mass \%= (Fat Mass/Body weight) $x$ 100).

Statistical analysis: Mean and standard deviation for the various parameters were computed. Analysis of variance was employed using Microsoft Excel (2007) Statistical Analysis Tool Pack. The least significant difference (LSD) was calculated at $5 \%$. Coefficients of correlation (r) at the significance of 1,5 and $10 \%$ were also derived to determine the relationship of body perception and stress with anthropometry, body fat, food consumption frequency and eating disorders among the subjects.

\section{RESULTS AND DISCUSSION}

Body perception: The average body perception score of the subjects in Group I, II and III was 34.42, 38.65 and 34.52(fig. 1). It was observed that more than half of the subjects had no concern with their shape i.e. body satisfaction was observed in $67 \%$ of the subjects from Group III, followed by $60 \%$ from Group I and $50 \%$ from Group II. On the other hand, a marked concern with body shape in terms of body dissatisfaction was observed in $8 \%$ of the Group II subjects, followed by $6 \%$ in Group I and lastly 5\% in Group III. A mild concern with body shape was high in Group II i.e. $35 \%$ subjects followed by Group III and least in Group I (Table 1). Jacobi and Fittig (2010) revealed the most possible predictor for eating pathology in women is body dissatisfaction. The prevalence of body dissatisfaction is common in middle-aged and older women because of changes of the body due to aging (McLaren and Kuh, 2004). Deeks and McCabe (2001) examined the effects of age on body image perceptions among middle-aged women from 35 to 65 years and found similar levels of body dissatisfaction and preoccupation with being overweight. Keel et al., (2007) found a significant association between weight dissatisfaction, dieting frequency and eating disorder symptoms in women and men from late adolescence to midlife. Pruis and Janowsky (2010) reported that body dissatisfaction remained constant throughout middle-life and late-life in women which was related to negative psychological outcomes and eating disorders (Rawana, 2013). Nevertheless, few women were satisfied with their bodies as they aged. In a study conducted by Lee (2013), a total of 69,57 and $36 \%$ of participants reported positive perceptions of their bodies during early, middle and late adulthood, respectively.

Stress Profile: The average stress score of the subjects in Group I, II and III was 18.34, 17.50 and 16.09 (fig 2)(fig 1). The perceived stress scores (table 1) revealed that $36 \%$ of the subjects from 
Bains, K. and Singh, A. / J. Appl. \& Nat. Sci. 10 (3): 1066-1072 (2018)

Table 1. Distribution of the subjects on the basis of body satisfaction perceived stress levels.

\begin{tabular}{|c|c|c|c|c|c|}
\hline Level & Score & $\begin{array}{l}\text { Group I } \\
(30-39 \text { yrs) } \\
n=53\end{array}$ & $\begin{array}{l}\text { Group II } \\
(40-49 \text { yrs) } \\
n=26\end{array}$ & $\begin{array}{l}\text { Group III } \\
(50-59 \text { yrs) } \\
n=21\end{array}$ & $\begin{array}{l}\text { Overall } \\
(n=100)\end{array}$ \\
\hline \multicolumn{6}{|l|}{ Body perception } \\
\hline No concern with Shape & Less than 38 & $32(60)$ & $13(50)$ & $14(67)$ & $59(59)$ \\
\hline Mild concern with Shape & 38 to 51 & $13(25)$ & $9(35)$ & $6(29)$ & $28(28)$ \\
\hline Moderate concern with Shape & 52 to 66 & $5(9)$ & $2(8)$ & 0 & $7(7)$ \\
\hline Marked concern with Shape & More than 66 & $3(6)$ & $2(8)$ & $1(5)$ & $6(6)$ \\
\hline \multicolumn{6}{|l|}{ Perceived stress level } \\
\hline Much lower than average & $0-7$ & $2(4)$ & $1(4)$ & 0 & $3(3)$ \\
\hline Slightly lower than average & $8-11$ & $3(6)$ & $4(15)$ & $2(10)$ & $9(9)$ \\
\hline Average & $12-15$ & $8(15)$ & $5(19)$ & $8(38)$ & $21(21)$ \\
\hline Slightly higher than average & $16-20$ & $20(38)$ & $10(38)$ & $7(33)$ & $38(38)$ \\
\hline Much higher than average & 21 above & $19(36)$ & $6(23)$ & $4(19)$ & $29(29)$ \\
\hline
\end{tabular}

Values in parenthesis are percentages (\%)

Table 2. Anthropometric profile and body fat of the subjects from three age groups.

\begin{tabular}{lllll}
\hline Parameter & $\begin{array}{l}\text { Group I } \\
\mathbf{( 3 0}-\mathbf{3 9} \text { yrs) } \mathbf{n}=\mathbf{5 3}\end{array}$ & $\begin{array}{l}\text { Group II } \\
\mathbf{( 4 0 - 4 9} \mathbf{~ y r s}) \mathbf{n}=\mathbf{2 6}\end{array}$ & $\begin{array}{l}\text { Group III } \\
\mathbf{( 5 0 - 5 9} \text { yrs) } \mathbf{n}=\mathbf{2 1}\end{array}$ & $\begin{array}{l}\text { LSD } \\
\text { at 5\% }\end{array}$ \\
\hline Weight $(\mathrm{kg})$ & $67.0 \pm 11.3$ & $72.1 \pm 15.3$ & $71.4 \pm 10.0$ & $\mathrm{NS}$ \\
Height $(\mathrm{cm})$ & $161.8 \pm 4.9$ & $161.3 \pm 5.4$ & $160.2 \pm 4.8$ & $\mathrm{NS}$ \\
Waist Circumference $(\mathrm{cm})$ & $81.6 \pm 10.9$ & $87.7 \pm 12.3$ & $88.2 \pm 10.1$ & 7.9 \\
Hip Circumference $(\mathrm{cm})$ & $102.3 \pm 9.6$ & $108.5 \pm 10.9$ & $110.8 \pm 7.3$ & 6.7 \\
Body Mass Index $\left(\mathrm{kg} / \mathrm{m}^{2}\right)$ & $25.7 \pm 4.3$ & $27.3 \pm 3.05$ & $27.8 \pm 3.4$ & $\mathrm{NS}$ \\
Waist to Hip Ratio & $0.79 \pm 0.06$ & $0.81 \pm 0.06$ & $0.81 \pm 0.09$ & $\mathrm{NS}$ \\
Fat $(\%)$ & $35.51 \pm 6.39$ & $39.1 \pm 6.9$ & $40.11 \pm 3.70$ & 4.31 \\
\hline
\end{tabular}

Values are Mean \pm Standard Deviation, LSD: Least Significant Difference, NS: Non significant

Table 3. Consumption frequency score of cereals, pulses, vegetables, fruit of beverages, sweets and snacks and eating out frequency of the subjects.

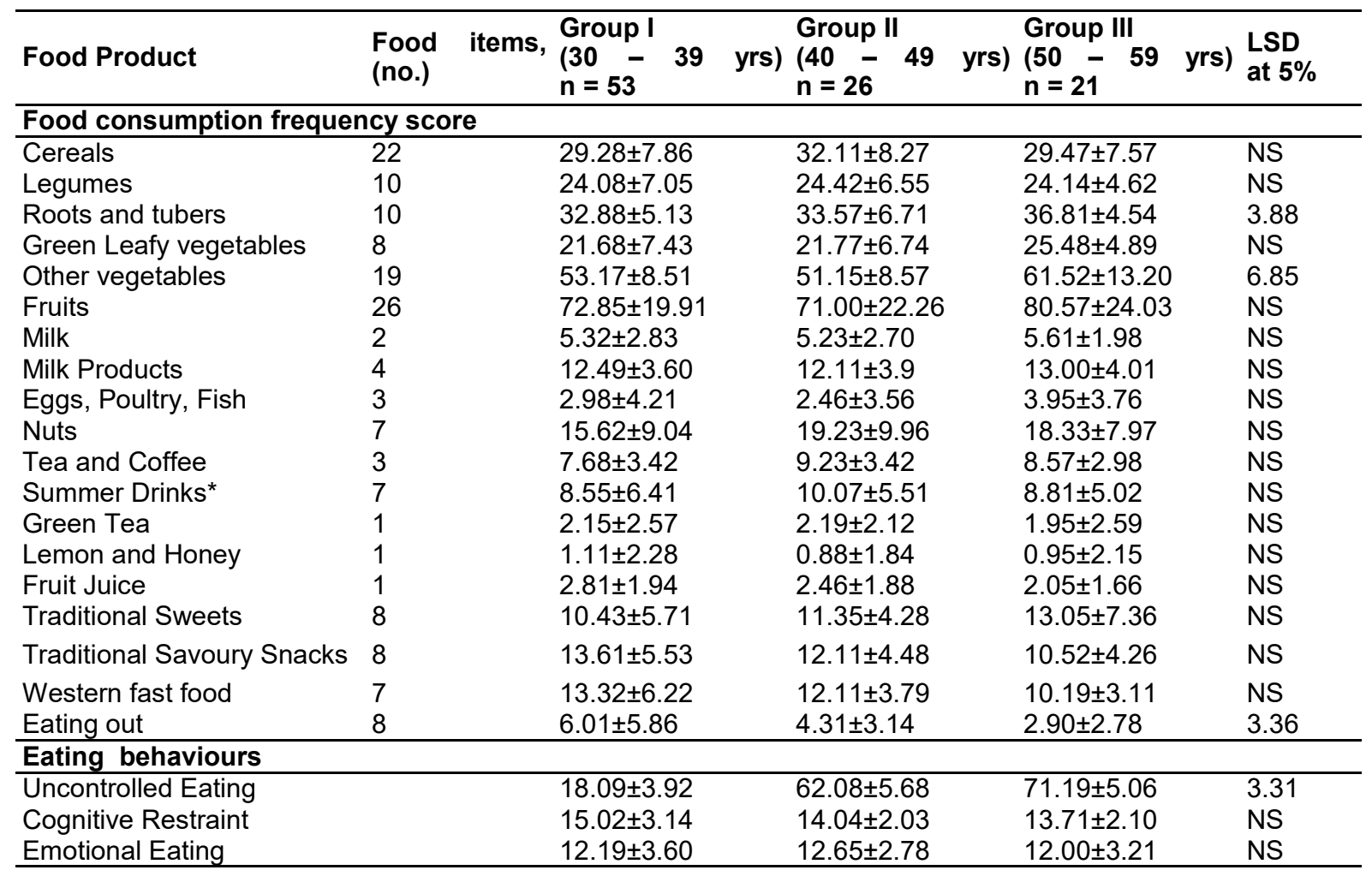

Values are Mean \pm SD; NS: Non-Significant; LSD: Least Significant Difference, *Summer drinks included shikanjee, ice tea, aam panna, jal jeera, kanji, sharbat and coconut water 
Table 4. Correlation coefficients among adiposity parameters and eating behaviours of 30 to 59 years old working women. $\mathrm{N}=100$

\begin{tabular}{|c|c|c|}
\hline \multirow{2}{*}{ Parameters } & \multicolumn{2}{|c|}{ Correlation coefficients ( $r$ ) } \\
\hline & Body satisfaction & Stress \\
\hline \multicolumn{3}{|c|}{ Anthropometric measurements and body fat } \\
\hline Body mass index & $0.59^{* \star *}$ & NS \\
\hline Body weight & $0.51^{\star * *}$ & NS \\
\hline Waist circumference & $0.45^{\star * *}$ & NS \\
\hline Body fat & $0.50^{* * *}$ & NS \\
\hline \multicolumn{3}{|l|}{ Food frequency } \\
\hline Traditional sweets & $0.29^{* \star *}$ & NS \\
\hline $\begin{array}{l}\text { Traditional savoury } \\
\text { snacks }\end{array}$ & NS & $0.32^{* \star *}$ \\
\hline Western fast food & NS & $0.29^{* * *}$ \\
\hline Eating out & NS & $0.34^{* * *}$ \\
\hline \multicolumn{3}{|l|}{ Eating disorders } \\
\hline Uncontrolled eating & $0.42^{\star \star \star}$ & NS \\
\hline Emotional eating & $0.33^{* * *}$ & $0.21^{* *}$ \\
\hline
\end{tabular}

NS: Non significant, *Significantat $10 \%$, ** Significantat $5 \%,{ }^{* *}$ Significant at $1 \%$

Group I exhibited the perceived stress level category "much higher than above" with very high health concern followed by Group II $(23 \%)$ and lastly Group III (4\%). The higher stress in younger age groups may be attributed to more family responsibilities such as taking care of young children. The least amount of stress was observed in both Groups I and II with 4\% subjects representing "much lower than average" stress level and very low health concern. The subjects in the Group I have scored statistically higher on their perceived stress scores as compared to their counterparts which signify the increased stress scenario being faced presently. A study by Matud (2004) suggested that women suffer more stress than men. . Cinamon and Rich (2002) reported women compared to men tend to experience higher levels of work-family conflict in trying to meet the responsibilities in both roles. In another study by Wiegner et al.,(2015) more than half of the subjects perceived more stress, women to a greater extent than men. A high level of perceived stress was accompanied by symptoms of depression and anxiety. Epel et al. (2000) and Kyrou et al. (2006) revealed that stress is highly correlated with the increased prevalence of adiposity and metabolic syndrome. Stress alters food choice by exhibiting preference for food items with higher content of fat and sweets which are generally considered rewarding (Oliver et al. 2000; Salbe et al. 2004).

Anthropometric measurements and body fat: The anthropometric parameters and body fat percentage of the subjects have been shown in table 2. The subjects in Group I, II and III had 17.9, 23.4 and $23.0 \%$ higher body weights, respectively when compared to the reference standards of $55.0 \mathrm{~kg}$ for adult women (ICMR, 2010). The younger age Group (30-39 years) had the lowest body weights; the data shows a gradual increase in the body weight as the age progresses from

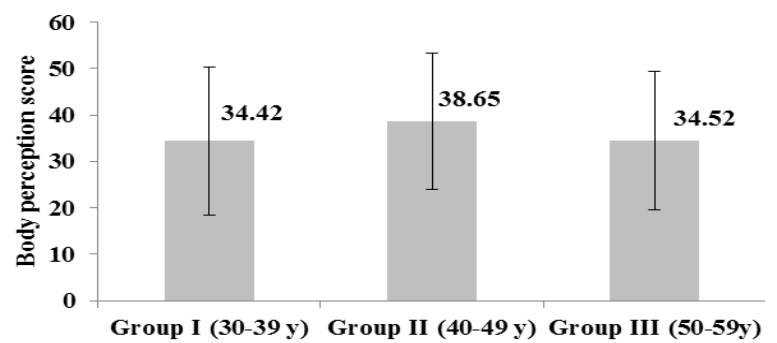

Fig. 1. Average body perception score of the subjects.

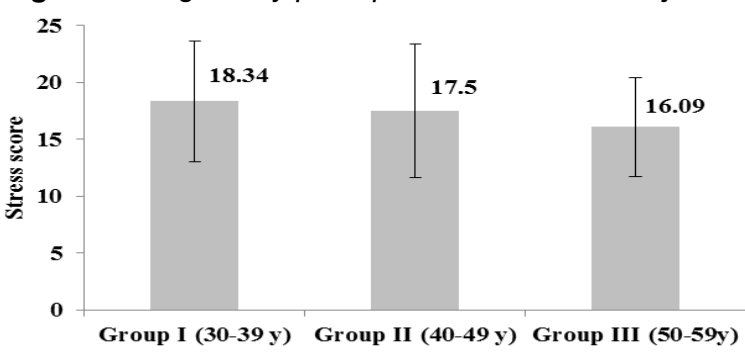

Fig. 2. Average stress score of the subjects

Group I to Group II and III. A significant difference was observed in the mean waist circumference of Group I $(81.6 \mathrm{~cm})$ and Group II $(87.7 \mathrm{~cm})$ as well as between the Groups I and III $(88.2 \mathrm{~cm})$. The subjects falling in Group I had the lowest waist circumference. The results revealed that all the subjects belonging to the different age groups were predisposed to the development of $a b$ dominal obesity which is one of the key factors in the development of metabolic diseases. According to Alberti et al. ,(2006) and Misra et al.,(2006) cutoff level for the categorization of abdominal obesity for South Asian women is $\geq 80 \mathrm{~cm}$, all the age categories in the present study had higher waist circumference than the cut-off value. According to the classification provided by Garrow et al.,(1981), a major proportion of the subjects from three different age groups were into the category of obese $\left(>25.0 \mathrm{~kg} / \mathrm{m}^{2}\right.$ ), the obesity prevalence being 56.6 , 76.92 and $76.19 \%$, respectively. WHO has set the cut-off value of BMl for obesity as $<23 \mathrm{~kg} / \mathrm{m}^{2}$ for South-Asians (WHO, 2004), on the basis of that $62.26,80.77$ and $90.48 \%$ of the subjects in the Group I, II and III were found to be obese. A cut off point of 0.8 for waist and hip ratio were taken as reference value (Ghafoorunissa and Krishnaswamy, 1994). On the basis of that, the abdominal obesity was found in $60.38,69.23$ and $90.47 \%$ of the subjects in three groups, respectively. A significantly $(p \leq 0.05)$ lesser body fat percent was observed in Group I as compared to Group II and Group III. From the above results, it can be interpreted that fat mass increases with the progression of age beyond 40 years. Nande et al., (2009) found that the mean body fat \% of the normal, overweight, obese grade I and obese grade II women in the age group of 18-70 years from Maharashtra was $27.2,30.9,37.6$ and $38.0 \%$. Comparing these values with the present study, the values of fat $\%$ are quite higher. Kaur et al., (2012) reported the mean fat $\%$ of $31-40$ years, $41-50$ years and $51-60$ years was $32.0,37.2$ and 39.2 
$\mathrm{kg}$, respectively. Dhir and Bains (2014) reported that the mean percent body fat of the female teachers belonging to the age group of $35-55$ years was ranged between 37.8 to $40.2 \mathrm{~kg}$.

Food consumption frequency: The subjects in Group III had significantly ( $p \leq 0.05)$ higher consumption of roots and tubers in comparison to the subjects in Group I. Similarly, Group III had significantly $(p \leq 0.05)$ higher consumption frequency of other vegetables in comparison to Group I and II. The consumption of other food groups namely cereals, legumes, fruits, milk and milk products, egg, poultry and fish and nuts did not differ significantly among the three age groups. The consumption frequency score for tea and coffee was found to be higher in Group II (9.23) followed by Group III (8.57) and Group I (7.68). The consumption frequency scores of green tea ranged between 1.95 and 2.15; lemon and honey between 0.88 to 1.11 ; of fruit juices 2.05 to 2.81 among the three groups. Though there was no significant difference in the consumption frequency score of green tea, lemon and honey as well as fruit juice among the three groups, however, the results suggested that these products were more popular among the younger age group in comparison to the two older age groups. The consumption frequency scores of summer drinks namely shikanjee, ice tea, aam panna, jal jeera, kanji, sharbat and coconut water were highest in Group II (10.07) followed by Group III (8.81) and Group I (8.55). The Indian summer drinks are usually high in sugars, hence, may be a factor contributing to obesity. According to the coffee consumption board India (2008), 100\% subjects preferred tea $(100 \%)$ over coffee $(94 \%)$ in North India, followed by the consumption of plain milk $(70 \%)$ and buttermilk $(25 \%)$. According to a study by Centre for Marketing in Emerging Economies (CMEE, 2014) (2014) conducted in Lucknow, 34\% subjects consumed green tea daily and $83 \%$ subjects preferred packaged fruit juice over fresh juice (66\%). The consumption frequency score of traditional Indian sweet items was maximum in Group III (13.05) followed by Group II (11.35) and Group I (10.43). Contrary to this, the highest consumption frequency score for traditional snacks and western foods was maximum in Group I (13.61 and 13.32) followed by Group II (12.11) and Group III (10.52 and 10.11). The results clearly indicated that the subjects in older age category had preference for traditional sweet items while younger age group preferred traditional savoury snacks as well as western foods. Frequency score for eating out was significantly ( $p \leq 0.05$ ) higher in the youngest age group, the consumption frequency score being 6.01 as compared to Group II (4.31) and III (2.90). According to a study conducted by CMEE (2014) in Lucknow, 25\% of the respondents went eating out every day.

Eating disorders: The mean values of uncontrolled eating domain observed are least in Group I (18.09) and maximum in Group III (71.19) as depicted in table 3 . A significantly ( $p \leq 0.05$ ) lower mean value of uncontrolled eating domain was observed in the subjects belonging to Group I in comparison to Group II and III. The mean values of the cognitive restraint domain were 15.02, 14.04 and 13.71 for Group I, II and III respectively. The restraint was found lesser in Group III followed by Group II and I. The mean values of emotional eating domain revealed not much difference in Group I (12.19), Group II (12.65) and III (12.00) but the value in Group II was higher as compared to other two groups. Boschi et al.,(2001) reported the mean values for normal weight and overweight subjects classified under cognitive restraint as 7.36 and 8.82 , under uncontrolled eating 3.64 and 5.87 , finally under emotional eating 3.24 and 3.87 respectively. In another study by Guillain et al., (2009), the median values for cognitive restraint, uncontrolled eating and emotional eating were $44.4,25.9$ and 44.4, respectively. Women tend to exhibit higher restraint and disinhibition scores when compared to men (Provencher et al., 2003; Lesdema et al., 2012). Anderson et al. (2002) reported cognitive restraint is associated with higher concentrations of cortisol thus causing stress. Dietary intake has been shown to be limited in women with high cognitive restraint (Mclean et al., 2001). The most robust predictor of the development of obesity and weight gain over time is disinhibition (Löffler et al. 2015; Bryant et al. 2008). Disinhibition was the attribute most strongly linked with both BMI and BF \%. However, (KeskiRahkonen et al., 2007) reported restrained eaters or dieters who attempt to restrict their food intake are more prone to overeat which contributes to obesity.

Relationship of body satisfaction and stress with overweight/obesity parameters, food consumption and eating disorders: The correlation coefficients ( $r$ ) computed among the various parameters such as body satisfaction and stress with overweight/obesity parameters, food consumption and eating disorders have been shown in table 4 . The statistical analysis revealed that body satisfaction perceived as lesser concern with body shape was positively and significantly $(p \leq 0.01)$ correlated with BMI, body weight, waist circumference and body fat, the values of ' $r$ ' being 0.59 , $0.51,0.45$ and 0.50 , therefore indicating that less concern with body shape among women is related to overweight and obesity. For the dietary factors, body dissatisfaction in terms of higher concern with body shape was significantly $(p \leq 0.05)$ correlated with lesser consumption frequency of traditional sweets $(r=-0.29)$. For eating behaviours, body satisfaction was found to be significantly $(p \leq 0.01)$ correlated with uncontrolled eating ( $r=$ $0.42)$ and emotional eating $(r=0.33)$. The results revealed that the greater concern with body shape among women is an important factor influencing adiposity, eating behaviours and food choices.

The perceived stress levels were not found to be significantly associated with parameters of overweight/obesity such as body weight, BMI, waist circumference and body fat. Among the dietary factors, the stress level showed a positive and 
significant $(p \leq 0.01)$ correlation with traditional savoury snacks $(r=0.32)$ and western fast food $(r=$ 0.29 ) among the subjects. The stress level was also significantly ( $p \leq 0.01,0.05)$ correlated with higher frequency of eating out $(r=0.34)$ and emotional eating as well $(r=0.21)$. Researchers suggest that stress is related to increased weight gain among viscerally overweight subjects as they eat to suppress stress and the choice comprises highly palatable and nutrient dense foods rich in fat and sugars (Warne, 2009). According to $\mathrm{Ng}$ and Jeffery (2003), women with high levels of perceived stress were associated with a higher fat diet. Simply stated, aversive states, such as stress, may motivate people to engage in unhealthy behaviours that bring them pleasure (Zillman and Bryant, 1985).

\section{Conclusion}

The findings concluded that lesser concern with body shape and stress were the prominent factors contributing towards adiposity as well as an altered food choice and eating behaviour. A higher preference for western fast foods and eating out was exhibited during stress. Uncontrolled eating behaviour was mostly observed in the later years and was least in the youngest age group. Emotional eating was observed during states of stress. Thus interventions in the form of educational programs aimed at behaviour and cognitive therapy could prove beneficial for long term weight and stress management as well as improving the eating behaviours.

\section{REFERENCES}

1. Alberti, S.G., Zimmet, P., Shaw, J. and Grundy,S.M. (2006). Metabolic syndrome: A new world-wide definition. Diabetic Med., 23: 469-480.

2. Anderson, A., Shapiro, R., Lundgren, D., Spataro, E. and Frye, A. (2002). Self-reported dietary restraint is associated with elevated levels of salivary cortisol. Appetite, 38: 13-17.

3. Benas, J.S., Uhrlass, D.J. and Gibb, B.E. (2010). Body dissatisfaction and weight-related teasing: A model of cognitive vulnerability to depression among women. J. Behav. Ther. Exp. Psychiatry, 41: 352-356.

4. Boschi, V., lorio, D., Margiotta, N., D'Orsi, P. and Falconi, C. (2001). The Three-Factor Eating Questionnaire in the evaluation of eating behaviour in subjects seeking participation in a dietotherapy programme. Ann.Nutr.Metab.,45: 72-77.

5. Bryant, J., King, A., Blundell, E. (2008). Disinhibition: its effects on appetite and weight regulation. Obes Rev., 9: 409-419.

6. Cappelleri, J.C., Bushmakin, A.G., Gerber, R.A., Leidy, N. K., Sexton, C.C., Lowe,M.R.and Karlsson, J. (2009). Psychometric analysis of the Three-Factor Eating Questionnaire-R21: results from a large diverse sample of obese and non-obese participants. Int. J.Obes.,33: 611-620.

7. Cinamon, R.G and Rich, Y. (2002). Gender differences in the importance of work and family. Sex Roles, 47: 531-541.

8. CMEE (2014). Centre for Marketing in Emerging Economics. Cited from: http://iimlcmee.org/food-andbeverage-preference-of-lucknowites-2/.Coffee Consumption in India 2008. Cited from: www.indiacoffee.org

9. Cohen, S., Kamarck, T. and Mermelstein,R.(1983). A global measure of perceived stress. J. Health Soc.Behav., 24: 385-396.

10.Deeks, A. A. and McCabe, M. P. (2001). Menopausal stage and age and perceptions of body image. Psychol. Health, 16: 367-379.

11.Dhir, R. and Bains,K.(2014). Anthropometric Profile of Adult Women As Influenced By Dietary Protein and Exercise. J. Human Ecol., 46:73-77.

12.Epel, E., McEwen, B., Seeman, T., Matthews, K., Castellazzo, G., Brownell, D. (2000). Stress and body shape: stress-induced cortisol secretion is consistently greater among women with central fat. Psychosom Med., 62: 623-632.

13.Evans, C. and Dolan, B. (1993). Body Shape Questionnaire: derivation of shortened "alternate forms". Int. J. Eat.Disord.,13: 315-321.

14.Finch, L.E. and Tomiyama,A.J.(2014).Stress-induced eating dampens physiological and behavioral stress responses. In: Ronald R. Watson (Ed.), Nutrition in the prevention and treatment of abdominal obesity. New York: Elsevier

15.Garg, C., Khan, S.A., Ansari, S.H and Garg, M. (2009). Prevalence of obesity in Indian women. Obes. Rev., S 1981.Treat obesity seriously. A Clinical Manual. Chutchill Livingstone, London.

16.Ghafoorunissa and Krishnaswamy (1994). Fatty acid composition of food items. In: Diet and Heart Disease. National Institute of Nutrition, Hyderabad, pp. 40-51.

17.Guillain, B.L., Romon, M., Musher-Eizenman, D., Heude, B., Basdevant, A., Charles, M.A. and Fleurbaix-Laventie Ville Santé Study Group. (2009). Cognitive restraint, uncontrolled eating and emotional eating: correlations between parent and adolescent. Matern. Child Nutr., 5: 171-178.

18. Harvard School of Public Nutrition 2014. cited from: http://www.hsph.harvard.edu/hpfs/hpfs_qx.htm

19. Haraldstad, K., Christophersen, K.A., Eide, H., Nativg, G.K. and Helseth, S. (2011). Predictors of health -related quality of life in a sample of children and adolescents: A school survey. J. Clin.Nurs., 20: 3048 -3056 .

20. ICMR (2010). Nutrient requirements and recommended dietary recommendations for Indians. Indian Council of Medical Research (ICMR), National Institute of Nutrition, Hyderabad.

21.Jacobi, C., Fittig, E. (2010) Psychosocial risk factors for eating disorders. In: Agras, S., editor. The Oxford Handbook of Eating Disorders. USA: Oxford University Press.

22.James, Philip T., Leach R., Kalamara E. And Shayeghi M. (2001). The worldwide obesity epidemic. Obes Res., 9: 228S-233S.

23.Joshi, S.R. (2003). Metabolic syndrome - emerging clusters of thelndian phenotype. J. Assoc. Physicians India, 51: 445-446.

24.Kaur, G., Bains, K. and Kaur,H.(2012). Body composition, dietary intake and physical activity level of sedentary adult Indian women. Food Nutr. Sci., 3: 1577-1585.

25.Keel, P.K., Baxter, M.G., Heatherton, T.F. and Joiner, T.E. (2007). A 20 -year longitudinal study of body weight, dieting, and eating disorder symptoms. J.Abnorm. Psychol., 116: 422-432.

26.Keski-Rahkonen, A., Bulik, C.M., Pietilainen, K.H., Rose, R.J., Kaprio, J. and Rissanen, A. (2007). Eating styles, overweight and obesity in young adult twins. Eur. J. Clin. Nutr., 61: 822-829.

27.Kyrou, I., Chrousos, G., Tsigos, C. (2006). Stress, 
visceral obesity and metabolic complications. Ann. N. Y Acad. Sci., 1083: 77-110.

28.Lee, M.S. (2013).Women's body image throughout the adult life span: Latent growth modeling and qualitative approaches. M.Sc. Dissertation, lowa State University, lowa.

29.Lesdema, A., Fromentin, G., Daudin, J., Arlotti, A., Vinoy, S., Tome, D., Marsset-Baglieri, A. (2012) Characterization of the Three-Factor Eating Questionnaire scores of a young French cohort. Appetite, 59: 385-390.

30.Löffler, A., Luck, T., Then, S., Sikorski, C., Kovacs, P., Böttcher, Y., Breitfeld, J., Tönjes, A., Horstmann, A., Löffler, M. (2015) Eating behaviour in the general population: An analysis of the factor structure of the German version of the three-factor-eatingquestionnaire (TFEQ) and its association with the body mass index. PLOS ONE, 10: e0133977.

31.Martin, J.B. (2010). The development of ideal body image perceptions in the United States. Nutr. Today, 45: 98-110.

32.Matud, M.P. (2004). Gender differences in stress and coping styles. Pers.Individ. Dif., 37:1401-1415.

33.McLaren, L. and Kuh, D. (2004). Body dissatisfaction in midlife women. J. Women Aging, 16: 35-54.

34.McLean, A., Barr, I., and Prior, C. (2001). Dietary restraint, exercise, and bone density in young women: Are they related? Medicine and Science in Sports and Exercise, 33: 1292-1296.

35.Misra, A., Vikram, N.K., Gupta, R., Pandey, R.M., Wasir, J.S and Gupta, V.P. (2006). Waist circumference cutoff points and action levels for Asian Indians for identification of abdominal obesity. Int. J.Obes., 30: 106-111.

36. Nande P, Hussain M and Vali S 2009. Influence of obesity on body measurements and composition in adult women belonging to minority community. Ind. $\mathrm{J}$. Nutr. Dietet., 47: 1347-1351.

37.NFHS -3 (2005-06) National Family Health Survey. International Institute for Population Sciences (IIPS) \& ORC MACRO (2007),India, Mumbai.

38.Ng, D.M. and Jeffery,R.W.(2003). Relationships between perceived stress and health behaviours in a sample of working adults. Health Psychol., 22: 638642.

39. Oliver, G., Wardle, J., Gibson, E. (2000). Stress and food choice: a laboratory study. Psychosom Med.,
62: 853-865.

40.Peat, C.M., Peyerl, N.L. and Muehlenkamp, J.J. (2008). Body image and eating disorders in older adults: A review. J. Gen. Psychol., 135: 343-358.

41.Provencher, V., Drapeau, V., Tremblay, A., Després, P., Lemieux, S. (2003). Eating behaviors and indexes of body composition in men and women from the Québec family study. Obes Res., 11: 783-792.

42.Pruis, A., Janowsky, S. (2010). Assessment of body image in younger and older women. Journal of General Psychology 137:225-238.

43.Rawana, S. (2013). The relative importance of body change strategies, weight perception, perceived social support, and self-esteem on adolescent depressive symptoms: Longitudinal findings from a national sample. Journal of Psychosomatic Research, 75:4954

44.Salbe, D., DelParigi, A., Pratley, E., Drewnowski, A., Tataranni, A. (2004). Taste preferences and body weight changes in an obesity-prone population. $\mathrm{Am} \mathrm{J}$ Clin Nutr79: 372-378.

45.Sheehan. T.J., DuBrava, S., DeChello,L.M.and Fang, Z.(2003). Rates of weight change for black and white Americans over a twenty year period. Int. J. Obes., 27: 498-504.

46.Tiggemann, M. and Lynch,J.E.(2001). Body image across the life span in adult women: The role of selfobjectification. Dev. Psychol., 37: 243-253.

47.Unnikrishnan, A.G., Kalra, S. and Garg, M.K. (2012). Preventing obesity in India: Weighing the options. Indian J. Endocrinol. Metab.,16: 4-6.

48.Warne, J.P. (2009) Shaping the stress response: interplay of palatable food choices, glucocorticoids, insulin and abdominal obesity. Mol. Cell Endocrinol., 300: 137-146.

49.WHO Expert Consultation (2004). Appropriate bodymass index for Asian populations and its implications for policy and intervention strategies. Lancet, 363:157 -163 .

50.Wiegner, L., Hange, D., Björkelund, C. and Ahlborg, G. (2015). Prevalence of perceived stress and associations to symptoms of exhaustion, depression and anxiety in a working age population seeking primary care an observational study. BMC Fam. Pract.,16: 38.

51.Zillman, D. and Bryant, J. (1985). Selective exposure to communication Hillsdale, NJ: Erlbaum, pp 157 190. 